\title{
LAMINAÇÃO TMCP DE CHAPAS GROSSAS PARA AÇOS ARBL MIÇROLIGADOS COM NIÓBIO, VANÁDIO E TITẦNIO LAMINADOS NA GERDAU OURO BRANCO*
}

\author{
Emanuelle Garcia Reis ${ }^{1}$ \\ Ricardo José de Faria ${ }^{2}$ \\ José Herbert Dolabela da Silveira ${ }^{3}$ \\ Rafael de Abreu Fraga ${ }^{4}$ \\ Romeu Thomaz Viana Júnior ${ }^{5}$ \\ Rodney Pardo Alves ${ }^{5}$ \\ Maurício Martins Pereira ${ }^{6}$
}

\section{Resumo}

Este trabalho apresenta as mais avançadas tecnologias do equipamento de resfriamento acelerado e têmpera direta da linha de laminação de chapas grossas da Gerdau Ouro Branco. O laminador de chapas grossas possui um conjunto de técnicas de última geração para controle de forma (Bending, Shifting e Smart Crown) integrado ao modelo matemático que define o esquema de passes ótimo em função das propriedades mecânicas objetivadas no produto final. Isso permite obter chapas grossas de aços microligados em várias classes de resistência mecânica de 600 a 1.200MPa e de boa tenacidade a $-60^{\circ} \mathrm{C}$.

Palavras-chave: Resfriamento acelerado; Têmpera direta; Laminação de chapas grossas; Propriedades mecânicas; Modelo matemático.

\section{TMCP ROLLING OF PLATES FOR HSLA STEELS MICROALLOYED WITH NIOBIUM, VANADIUM AND TITANIUM ROLLED ON GERDAU OURO BRANCO}

\begin{abstract}
This paper presents the most advanced technologies of the accelerated cooling and direct quenching equipment of Gerdau Ouro Branco plate mill. Plate mill has a set of state-of-the-art techniques for shape control (Bending, Shifting and Smart Crown) integrated to the mathematical model that defines the optimal passes schedule in function of the mechanical properties objectified in the final product.This makes it possible to obtain thick plates of micro-alloyed steels in various strength classes of 600 to $1200 \mathrm{MPa}$ and good toughness at $-60^{\circ} \mathrm{C}$.
\end{abstract}

Keywords: Accelerated colling; Direct quenching; Plate mill; Mechanical properties; Mathematical model.

1 Engenheiro Civil, M. Eng., Assessor Técnico, Gerência de Chapas Grossas, Gerdau Ouro Branco, MG, Brasil.

2 Engenheiro Metalurgista, M. Eng., Assessor Técnico, Gerência de P\&D, Gerdau, Ouro Branco, MG, Brasil

3 Engenheiro metalurgista, M. Eng,, Gerente da laminação de chapas grossas, Gerdau Ouro Branco.

4 Engenheiro Metalurgista, Assessor Técnico, Gerência de Laminação de Chapas Grossas, Gerdau, Ouro Branco, MG, Brasil.

5 Engenheiro Metalurgista, Assessor Técnico, Gerência de P\&D, Gerdau, Ouro Branco, MG, Brasil

6 Engenheiro Metalúrgico, Chefe da Linha de Laminação de Chapas Grossas, Laminação de Chapas Grossas, Gerdau, Ouro Branco, MG, Brasil.

7 Engenheiro Metalúrgico, Assessor Técnico de Laminação, Laminação de Chapas Grossas, Gerdau, Ouro Branco, MG, Brasil. 


\section{INTRODUÇÃO}

Laminação controlada seguida de resfriamento acelerado, conhecido mundialmente como TMCP, tem por objetivo aumentar a resistência mecânica sem deterioração da tenacidade, o que é obtido através da alteração da microestrutura, de ferrita-perlita para, normalmente, ferrita e bainita finas. O princípio do processo consiste em se promover o resfriamento das chapas com velocidades rápidas ao longo da faixa de temperaturas de transformação.

Os benefícios mais frequentemente citados do emprego do resfriamento acelerado são (1):

- Possibilidade de obtenção do nível de resistência mecânica desejado com o emprego de menores teores de carbono e de elementos de liga e/ou de microliga,

- Resistência mecânica elevada com tenacidade adequada,

- Possibilidade de aumento da produtividade no caso de aços com requisitos pouco rigorosos de tenacidade, em função do emprego de condições de laminação controlada menos severas, tais como uma maior temperatura de acabamento ou uma menor espessura do esboço,

- Possibilidade de consolidação de classes de composição química e, eventualmente, de redução de projetos de ligas, através do emprego de taxas mais elevadas de resfriamento para obtenção da resistência mecânica desejada nas chapas de maior espessura,

- Desenvolvimento de novos produtos.

O processo de resfriamento acelerado só é totalmente efetivo quando controlado de maneira integrada, uma vez que, sozinho, não é capaz de assegurar melhorias significativas nas propriedades finais dos aços. As etapas de reaquecimento, de laminação e de resfriamento herdam, cada uma, os fenômenos físicos e metalúrgicos da etapa anterior. Portanto, para se obter uma microestrutura que atenda às propriedades mecânicas desejadas, é necessário considerar esses fenômenos em todas as etapas, desde a fabricação do aço líquido (Figura 1).

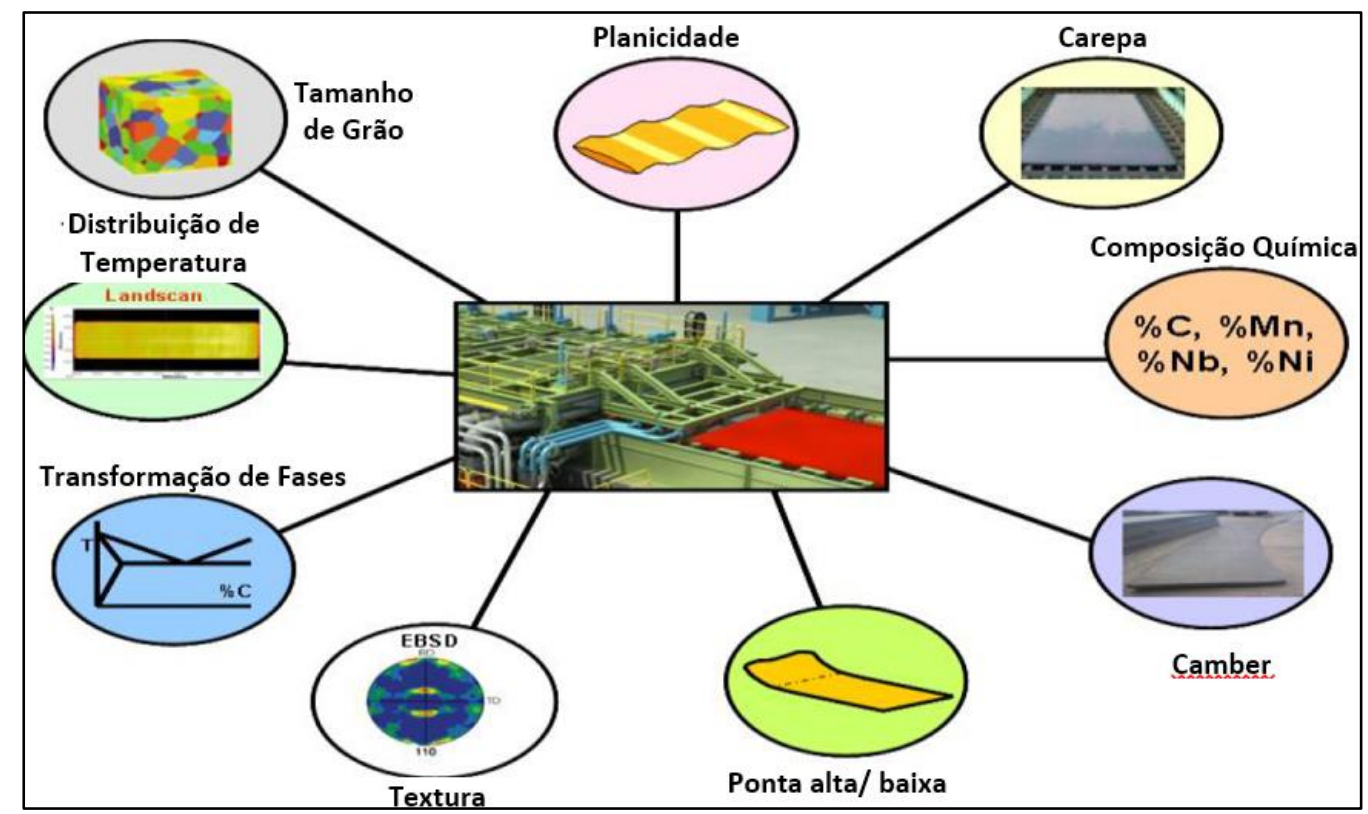

Figura 1. Principais características para a garantia da qualidade. 
A figura 2 representa esquematicamente o esquema de deformações e de temperaturas nos passes e as transformações de fases que ocorrem no processo de resfriamento acelerado.

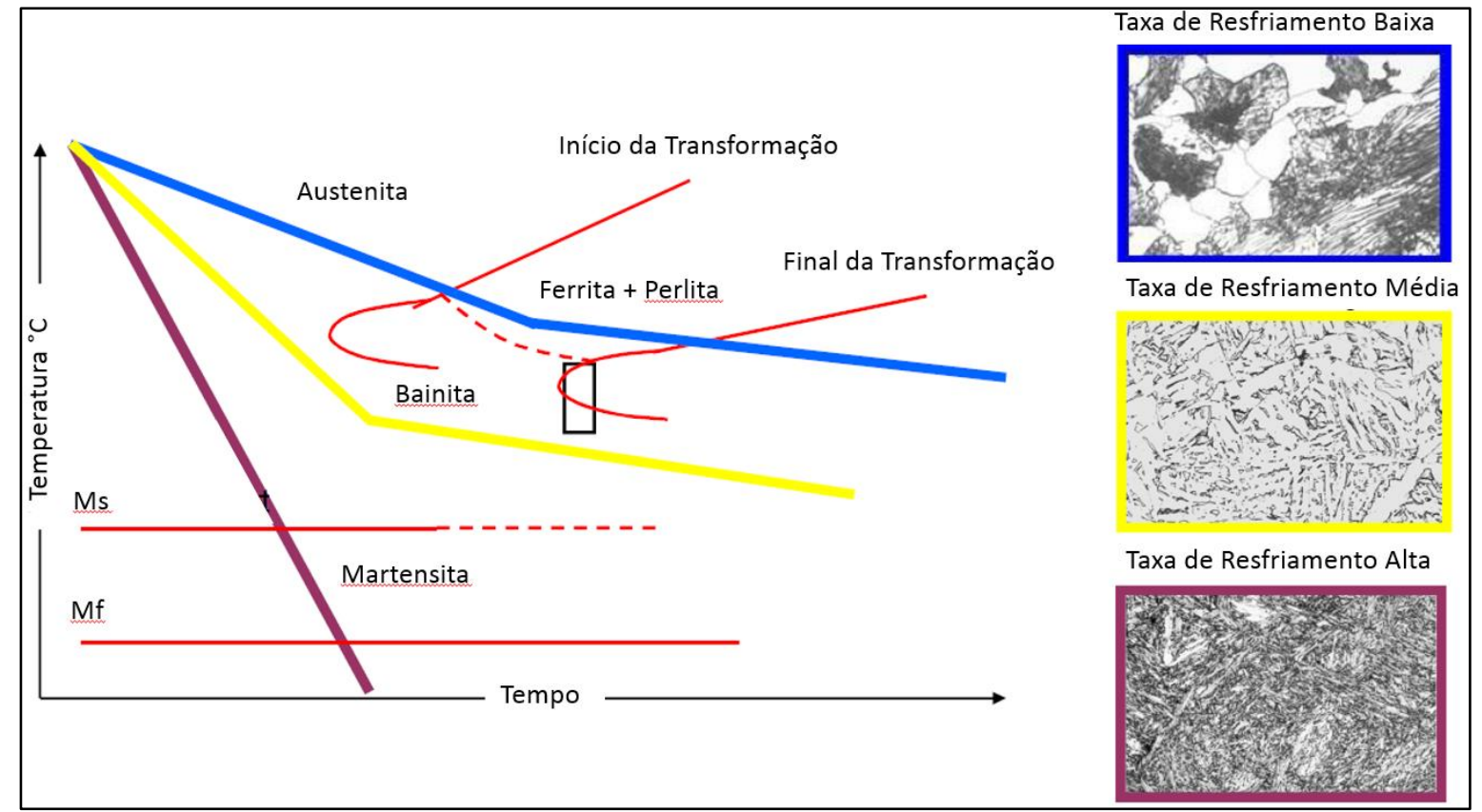

Figura 2: Desenho esquemático do processo de laminação controlada ${ }^{(2)}$.

Um aço adequadamente projetado e processado deve exibir níveis mínimos aceitáveis de várias propriedades importantes (Figura 3) à sua aplicação. De um modo geral, as propriedades de maior interesse nos aços estruturais são a resistência mecânica, a ductilidade ou a conformabilidade, a resistência tanto à fratura dúctil quanto à fratura frágil e a soldabilidade. Aços de sucesso devem apresentar níveis adequados de cada uma dessas propriedades, as quais, à exceção da soldabilidade, são controladas principalmente pela microestrutura final. Outra propriedade de grande importância em chapas grossas é a resistência à propagação de fraturas frágeis, que é fundamentalmente dependente da obtenção de um alto grau de refinamento da microestrutura final.

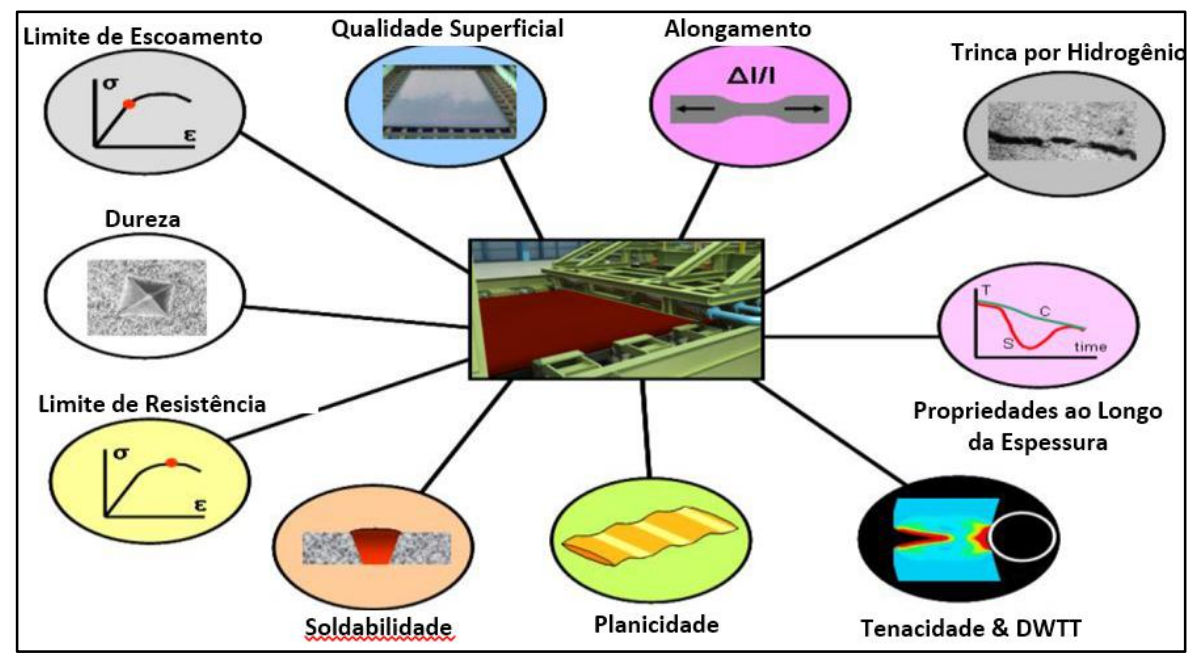

Figura 3. Exemplos de requisitos da qualidade da chapa final. 
$\mathrm{Na}$ Gerdau Ouro Branco, a Linha de Laminação de Chapas Grossas tem um equipamento de resfriamento acelerado denominado MULPIC (multi proposed interrupted cooling) (Figura 4). O MULPIC resfria esboços de forma homogênea e uniforme ao longo do comprimento e da largura, com uma elevada faixa de amplitude de controle de fluxo de água para atender a uma ampla gama de produtos. O MULPIC está situado entre a pré- desempenadeira e a desempenadeira a quente. A Pré-desempenadeira tem o objetivo de garantir que os esboços (material que vem do laminador) estejam planos para que o resfriamento acelerado seja 0 mais uniforme possível.

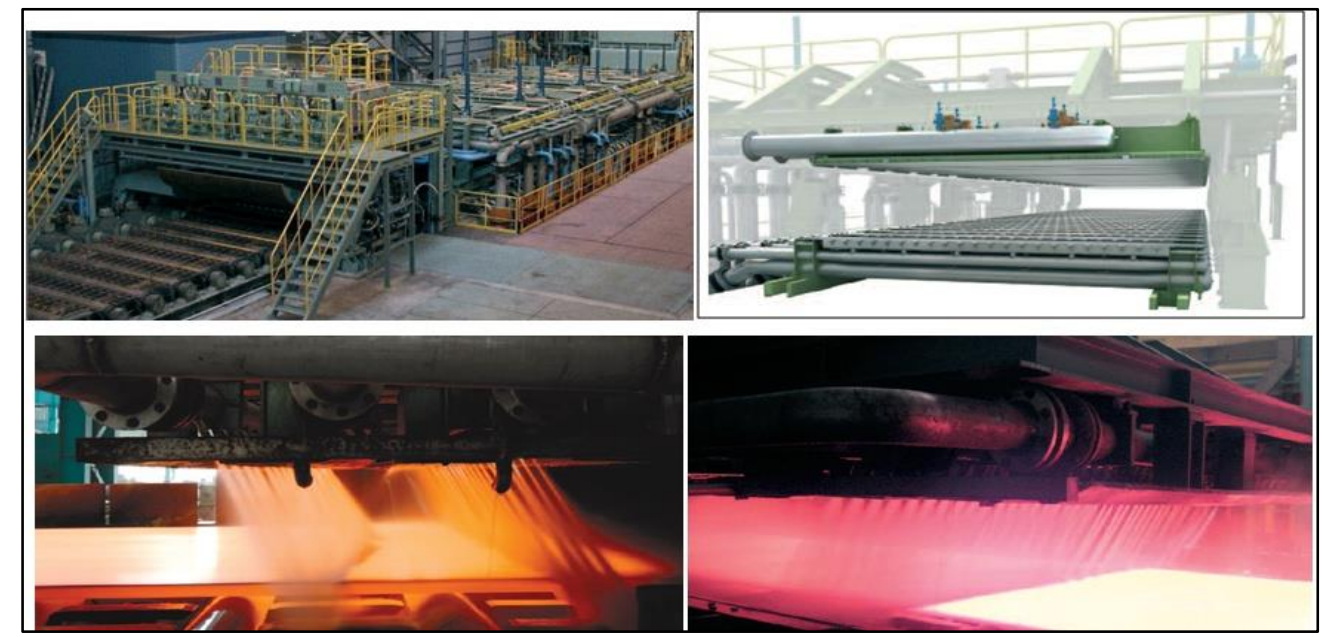

Figura 4. Equipamento de resfriamento acelerado (MULPIC).

O MULPIC possui dois modos de operação para resfriamento, resfriamento acelerado (ACC) ou têmpera direta (DQ) (Figura 5). Dependendo do tipo de resfriamento, obtêm-se microestruturas diferentes e consequentemente propriedades mecânicas diferentes.

O resfriamento acelerado (ACC) inicia-se logo após o término da laminação e termina em uma temperatura intermediária, seguindo-se o resfriamento ao ar. Geralmente é aplicado entre $800^{\circ} \mathrm{C}$ e $500^{\circ} \mathrm{C}$.

A têmpera direta (DQ) é um tipo de resfriamento que ocorre deforma mais intensa, terminando sob temperaturas mais baixas. Geralmente é aplicado entre $900^{\circ} \mathrm{C}$ e $200^{\circ} \mathrm{C}$.

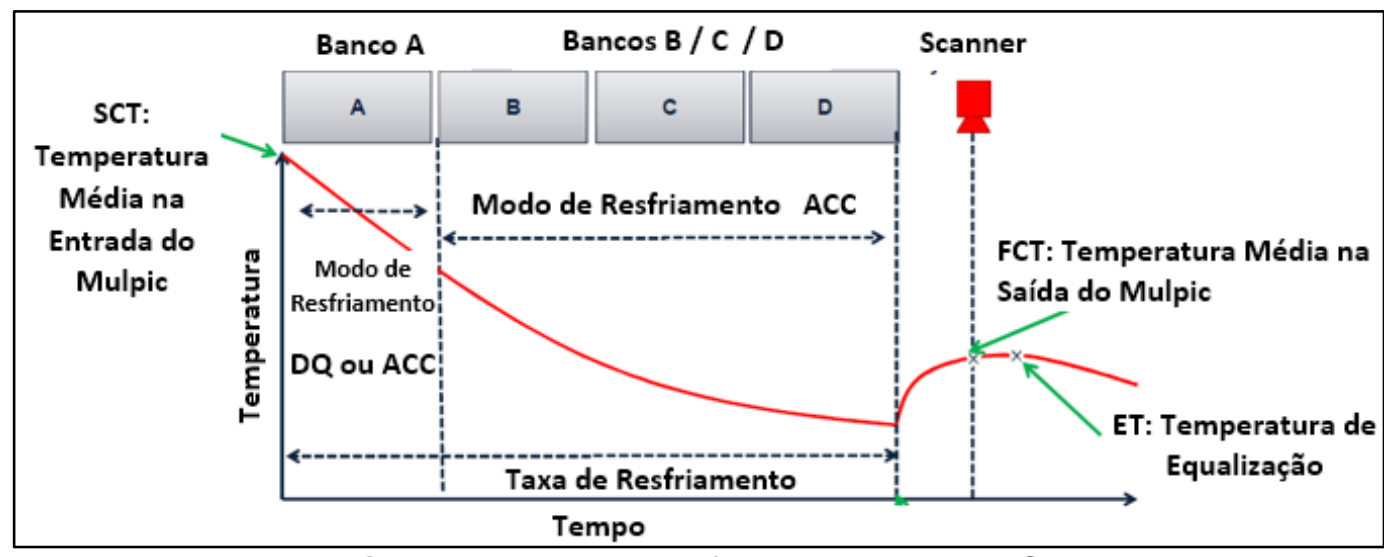

Figura 5. Modos de resfriamento do MULPIC. 
O equipamento possui controles que uniformizam a temperatura durante o processo de resfriamento (Figura 6). Estes controles são:

1. Controle de vazão ao longo da largura (water crown),

2. Controle de resfriamento nas bordas do esboço (edge masking),

3. Controle de resfriamento no topo e base do esboço (Head/Tail Masking),

4. Ajuste de velocidade (Speed Control),

5. Controle de vazão nas faces superior e inferior do esboço (Top and Bottom Flow Ratio Control).

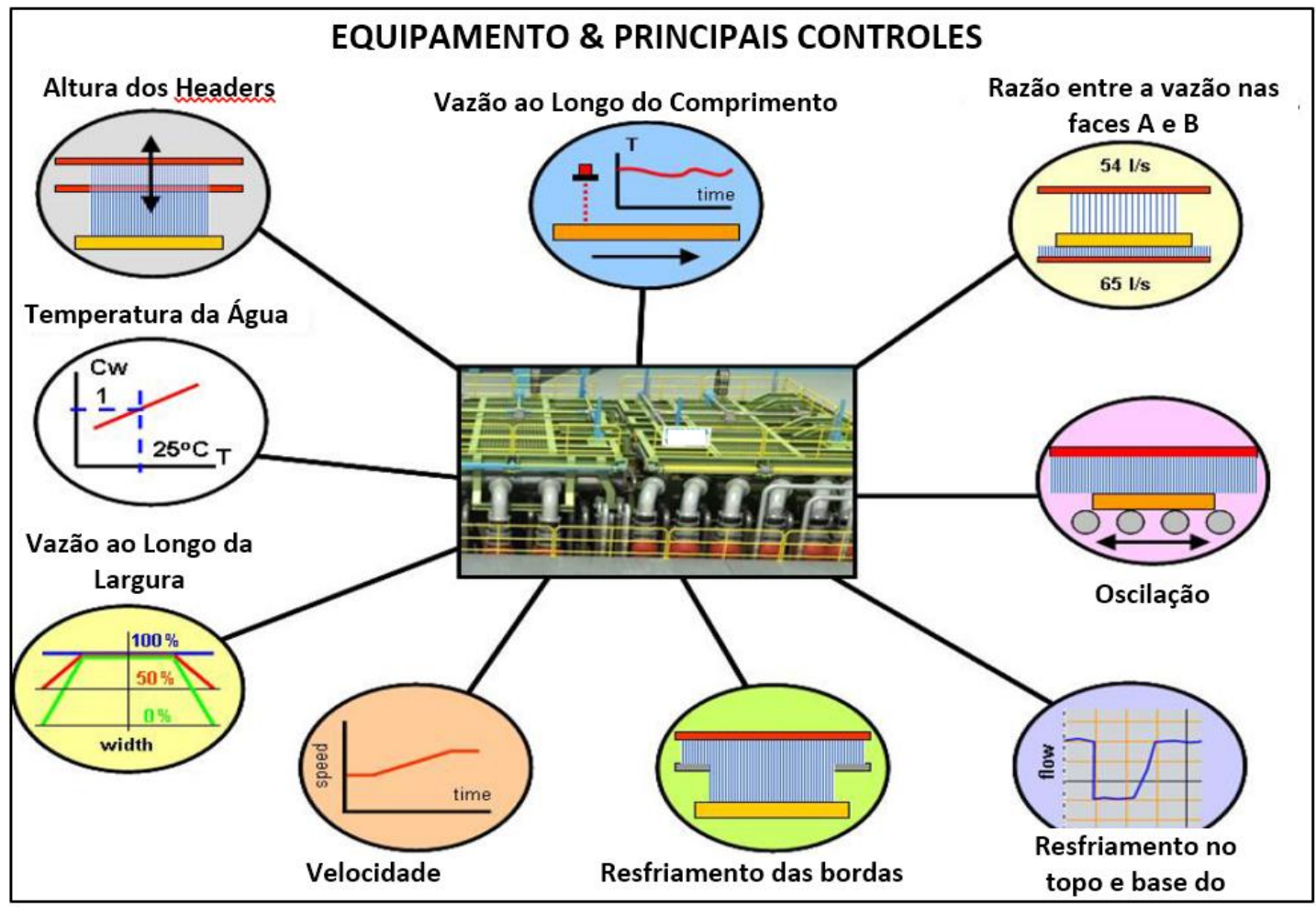

Figura 6. Equipamento e principais controles.

\section{MATERIAIS E MÉTODOS}

Foram realizadas várias laminações a quente com resfriamento acelerado. As temperaturas de início de resfriamento variando de $900^{\circ} \mathrm{C}$ a $670^{\circ} \mathrm{C}$, temperaturas final de resfriamento variando de $550^{\circ} \mathrm{C}$ a $150^{\circ} \mathrm{C}$ e taxas de resfriamento de $85^{\circ} \mathrm{C} / \mathrm{s}$ a $4^{\circ} \mathrm{C} / \mathrm{s}$.

A seguir serão citados os principais controles de processo para a garantia da forma, dimensões e propriedades mecânicas do esboço final:

\section{1- Processo de Aquecimento:}

O controle preciso do reaquecimento da placa é um fator chave em materiais com resfriamento acelerado.

Após o processo de reaquecimento, a placa deve apresentar temperatura uniforme, tamanho de grão austenítico uniforme e carepa superficial facilmente removível. As heterogeneidades térmicas e microestruturais na placa são herdadas pela chapa laminada e tendem a aumentar ainda mais durante o resfriamento acelerado. Isso, 
por sua vez, resulta em problemas de planicidade, elevado nível de tensões internas e variação das propriedades mecânicas. 
A temperatura de desenfornamento é definida em função do balanço desejado entre resistência mecânica e tenacidade. Atualmente variam de $1.000^{\circ} \mathrm{C}$ a $1.250^{\circ} \mathrm{C}$. $\mathrm{O}$ tempo de reaquecimento também é definido, evita-se tempos maiores pois podem causar crescimento de grão austenítico, prejudicar as propriedades mecânicas do aço, aumentar as perdas por carepa e reduzir a produtividade do forno.

\section{2- Esquema de Passes}

Para determinadas aplicações, é possível realizar o resfriamento acelerado imediatamente após a laminação a quente convencional ou a laminação de recristalização. No entanto, as melhores combinações de propriedades, especialmente o balanço entre resistência mecânica e tenacidade, são obtidas quando o resfriamento acelerado é aplicado após laminação controlada, que é a forma de processamento em que se obtém o máximo refino de grão.

O principal objetivo da laminação controlada é a maximização da formação de sítios no interior dos grãos, os quais são operacionalizados com o emprego do resfriamento acelerado.

$\mathrm{Na}$ maioria dos casos, a etapa de acabamento é realizada em temperaturas um pouco acima da temperatura de início da decomposição da austenita e, em alguns casos, o acabamento pode até ser feito abaixo dessa temperatura, na região bifásica $(\alpha+\gamma)$.

Em termos dimensionais, a principal função da laminação é produzir uma chapa plana e na espessura correta e uniforme.

O controle de planicidade é mais crítico do que na laminação controlada convencional, uma vez que o resfriamento com água tende a amplificar os defeitos de planicidade.

O laminador de chapas grossas da GERDAU possui modelos matemáticos de cálculo do esquema de passes com múltiplos setups ao longo do comprimento da chapa, esquema de passes com otimização durante a laminação, controle dinâmico de perfil, controle de forma, smart crown, controle de deslocamento de cilindros (shifting), flexão dos cilindros (bending), modelo de controle de forma e perfil do material (plan view), modelo de previsão de propriedades mecânicas e modelo matemático de controle de no resfriamento acelerado.

Todas essas funções tecnológicas são totalmente integradas através do sistema de automação ${ }^{(3,4)}$. Isto inclui o planejamento e controle de produção, modelos matemáticos e controle do processo e os equipamentos elétricos básicos (medidores on-line e motores). Garantido assim a qualidade em todos os processos.

A figura 7 mostra um exemplo de simulação de um esquema de passes com laminação controlada. 


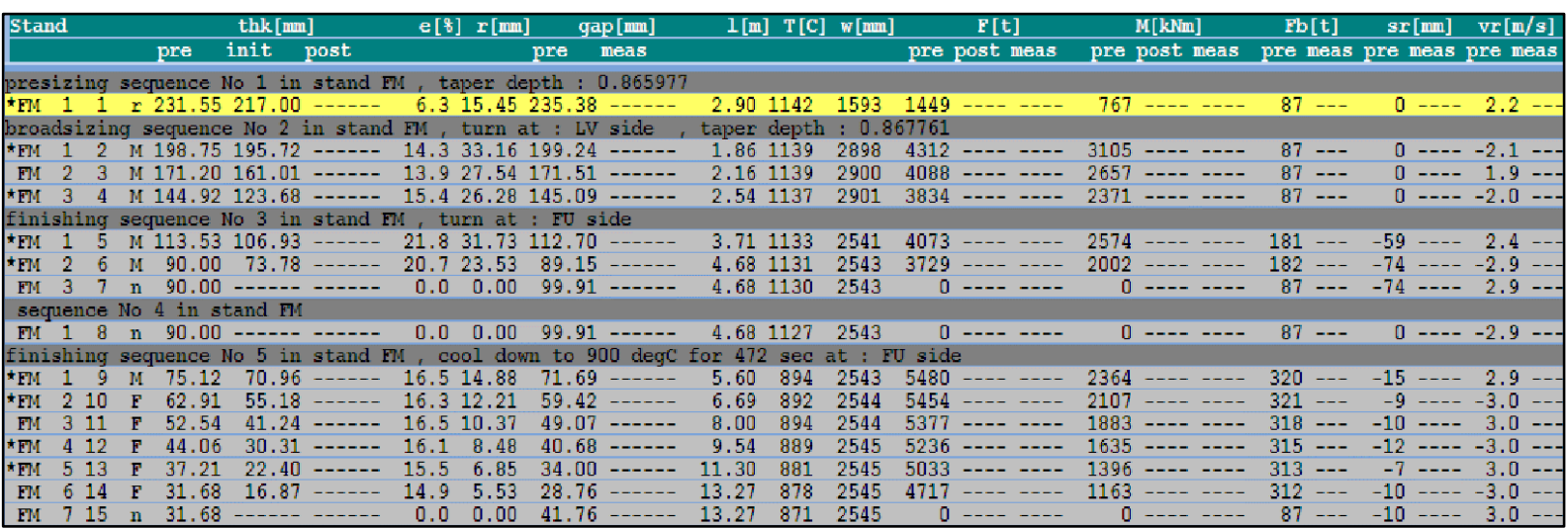

Figura 7. Exemplo de simulação de um esquema de passes com laminação controlada.

A estratégia de descamação é um fator de extrema importância e que deve ser definido com muita cautela. A quantidade de cada óxido presente e a espessura total da carepa dependem das condições de descarepação e de laminação empregadas.

A condutividade térmica da carepa é da ordem de $0,2 \mathrm{~W} / \mathrm{m}^{\circ} \mathrm{C}$, muito inferior à condutividade térmica do aço, que é de cerca de $35 \mathrm{~W} / \mathrm{m}^{\circ} \mathrm{C}$ na temperatura de $800^{\circ} \mathrm{C}$. Devido a essa grande diferença, a carepa atua como um isolante térmico (5). Assim, quando um meio de resfriamento é aplicado (água, por exemplo), a superfície da carepa é resfriada a uma temperatura muito mais baixa do que a da interface carepa/aço, de modo a manter constante o fluxo de calor através do aço e das camadas de carepa. Observa-se que o gradiente de temperatura é muito mais abrupto ao longo da espessura da carepa, em função de sua reduzida condutividade térmica.

É importante que a espessura da carepa seja uniforme, de forma a assegurar um resfriamento uniforme ao longo de toda a superfície da chapa (Figura 8). Caso contrário, haverá uma distribuição não uniforme de tensões térmicas, podendo causar sérios problemas de planicidade.

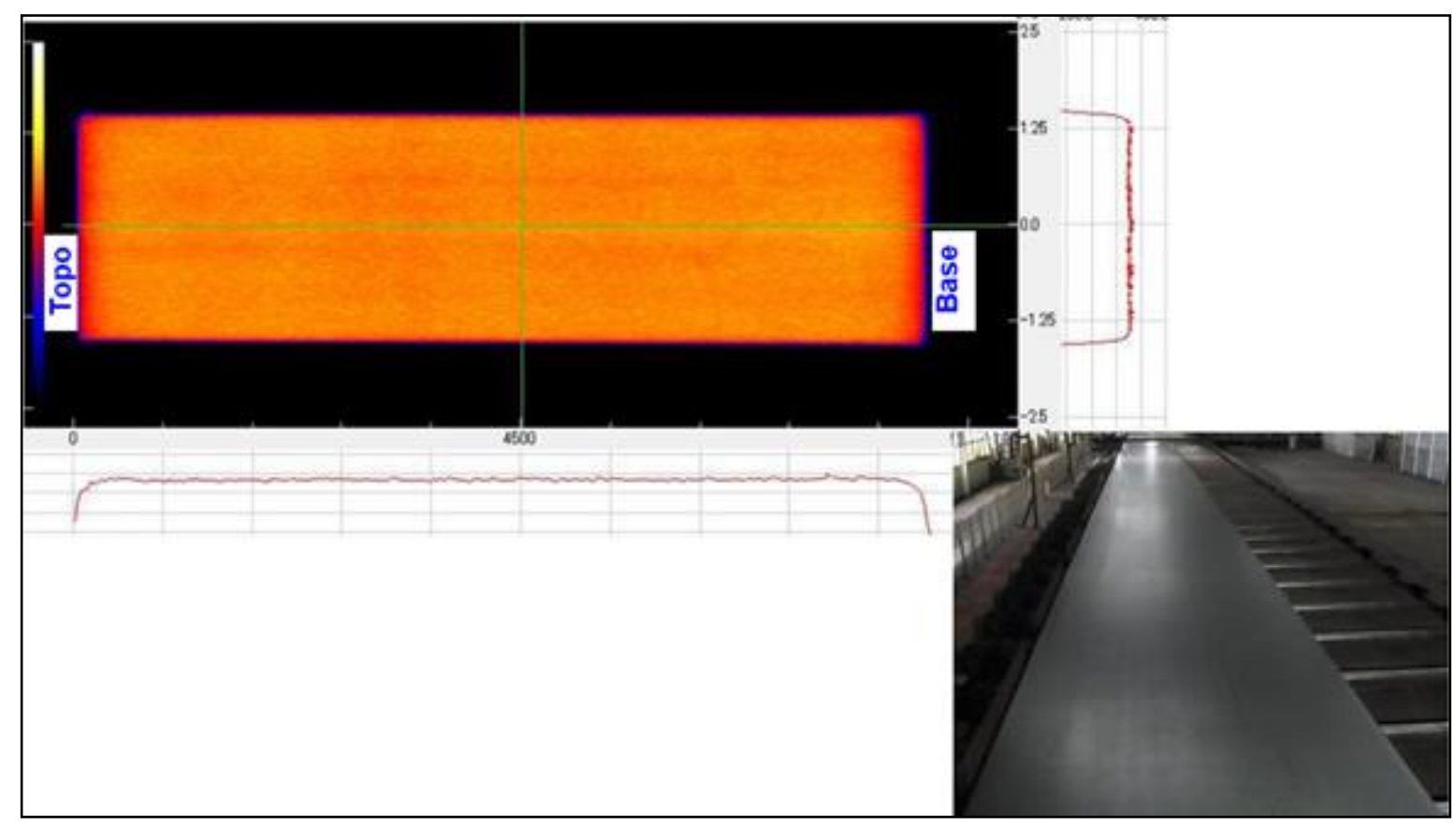

Figura 8: Exemplo de temperatura uniforme e boa planicidade num esboço. 


\section{3 - Controle do resfriamento}

Os aspectos mais importantes que devem ser levados em consideração durante 0 resfriamento são:

- Resfriamento do esboço de maneira uniforme nas direções da espessura, da largura e do comprimento (Figura 9)

- Controle da taxa de resfriamento de maneira uniforme (Figura 10),

- Estabilidade e reprodutibilidade operacionais;

- Conhecimento das temperaturas da chapa antes e após o resfriamento. Além das medidas da temperatura superficial, é fundamental que se disponha também de um modelo de cálculo para estimativa do perfil de temperatura através de toda a chapa.

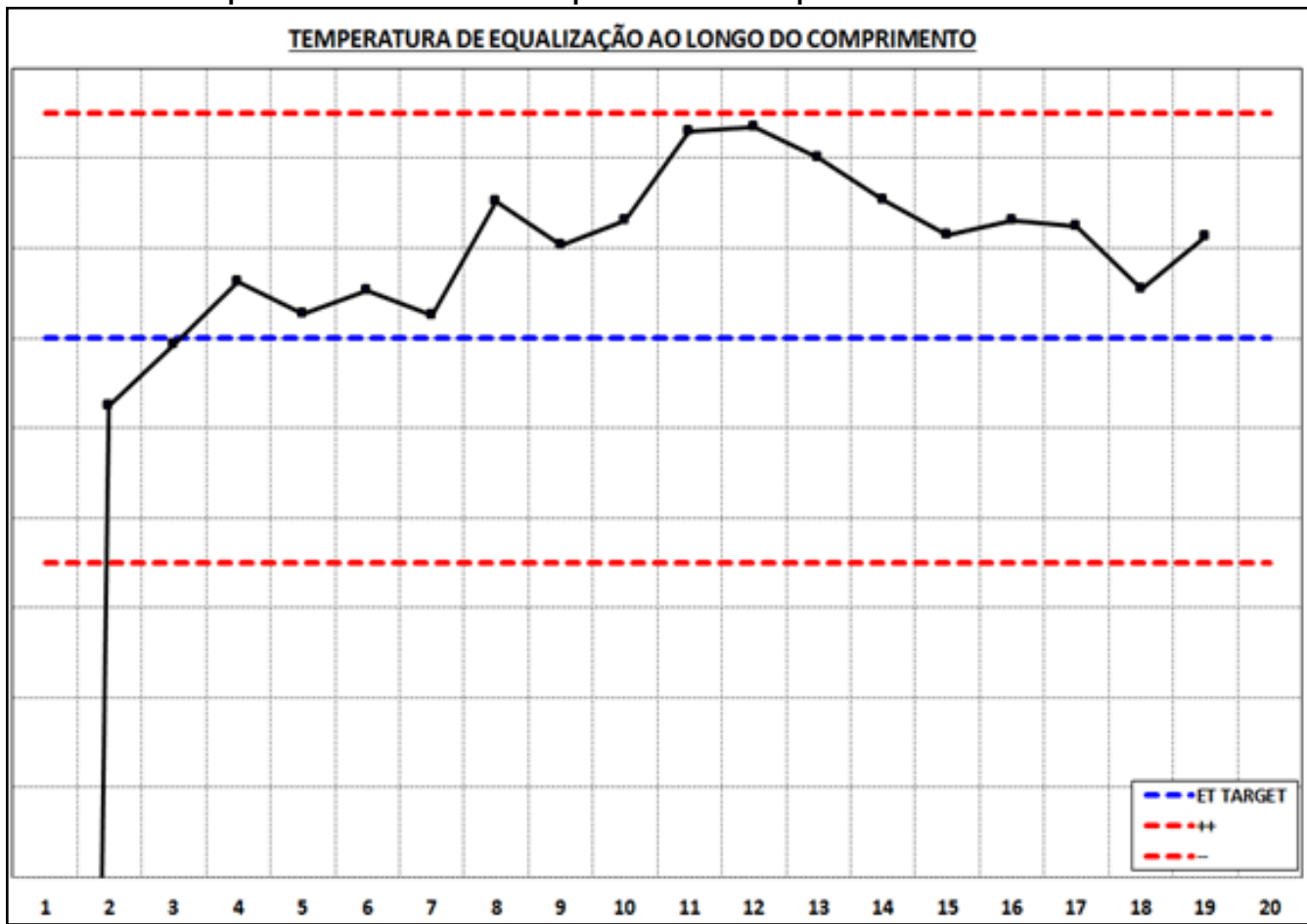

Figura 9: Exemplo de boa homogeneidade ao longo do comprimento da temperatura de equalização.

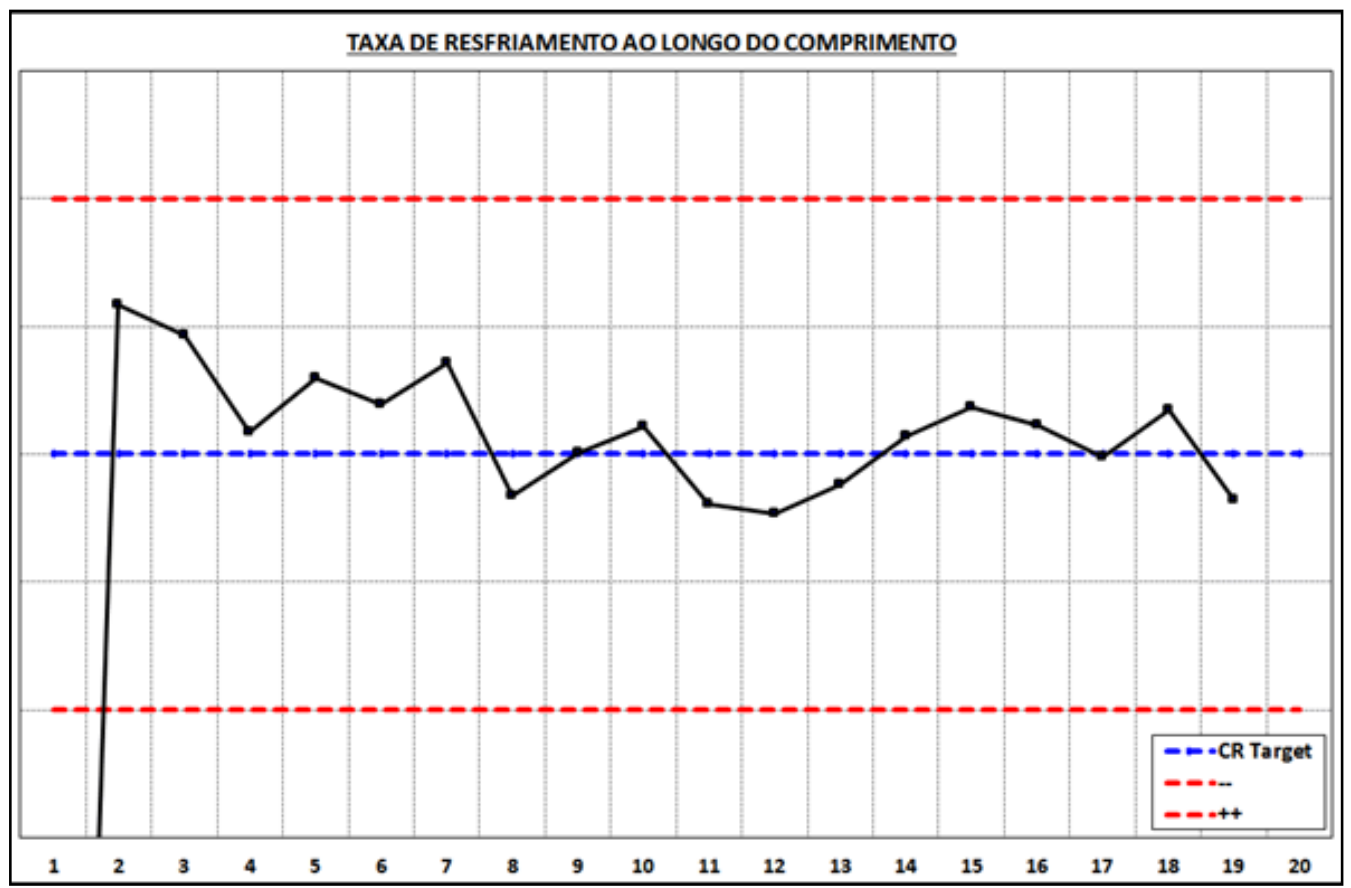


Figura 10: Exemplo de boa homogeneidade ao longo do comprimento da taxa de resfriamento.

\section{4 - Controle do desempeno}

O principal objetivo do processo de desempeno é controlar a planicidade final da chapa reduzindo as tensões residuais existentes e igualando o comprimento das tiras/fibras nas direções principais.

A chapa aparenta estar plana, porém dentro da chapa estão distribuídas tensões residuais não homogêneas, nos sentidos da espessura, do comprimento e da largura. Essa tensão vai aumentando de tamanho, de tal forma que uma hora a chapa não pode mais suportar, gerando assim a deformação da chapa.

O emprego da pré-desempenadeira permite que a chapa entre no MULPIC com uma condição ótima de planicidade, o que resulta em melhoria significativa em termos de uniformidade de resfriamento, em função do fluxo uniforme de água sobre a superfície da chapa. Como consequência, obtêm-se uma melhoria da planicidade final e uma redução das variações de propriedades mecânicas ao longo da largura e do comprimento da chapa.

A pré desempenadeira e a desempenadeira a quente da GERDAU possui cápsulas hidráulicas, sistema de bending e modelamento matemático visando a assegurar um grau suficiente de deformação para obter um esboço final com planicidade especificada pelo cliente.

Neste estudo, foram usados três tipos de aços microligados básicos com $\mathrm{Nb}, \mathrm{V}$ e $\mathrm{Ti}$ combinados com diferentes teores de $\mathrm{Cr}$, Mo e $\mathrm{B}$. O aço microligado ao $\mathrm{B}$ foi processado via $D Q$, enquanto que os outros dois foram produzidos via $A C C$, utilizando-se taxas de resfriamento distintas.

\section{RESULTADOS E DISCUSSÃO}

As tabelas 1 e 2 mostram os resultados de propriedades mecânicas em chapas grossas utilizando diferentes microligantes e em diferentes condições de processo.

Os aços 1 e 2 foram submetidos ao mesmo processo ACC, entretanto com diferentes taxas de resfriamento. Neste caso os valores de resistência mecânica e energia foram similares, o que mostra a efetividade e a flexibilidade do processo mesmo utilizando diferentes ligas e diferentes condições.

Por sua vez, o aço 3 foi submetido ao processo DQ, e como era de se esperar neste caso, foram obtidos os maiores valores de propriedades de resistência mecânica.

As figuras 11 (a) e 11 (b) mostram as microestruturas características obtidas para os aços 2 e 3 . As imagens mostram que a acicularidade na microestrutura aumenta com a severidade do processo de resfriamento. 
Tabela 1. Propriedades mecânicas de tração obtidas em esboços com diferentes parâmetros de resfriamento no MULPIC e composições químicas.

\begin{tabular}{|c|c|c|c|c|c|c|c|}
\hline $\begin{array}{c}\text { Tipo de } \\
\text { Aço }\end{array}$ & Microligantes & $\begin{array}{c}\text { Modo de } \\
\text { Operação } \\
\text { MULPIC }\end{array}$ & $\begin{array}{c}\text { Taxa } \\
\left({ }^{\circ} \mathrm{C} / \mathrm{s}\right)\end{array}$ & $\begin{array}{c}\mathrm{LE} \\
\text { médio } \\
(\mathrm{MPa})\end{array}$ & $\begin{array}{c}\text { LR } \\
\text { médio } \\
(\mathrm{MPa})\end{array}$ & $\begin{array}{c}\text { LE/LR } \\
\text { médio }\end{array}$ & $\begin{array}{c}\text { Along. } \\
\text { médio } \\
(\%)\end{array}$ \\
\hline 1 & $\mathrm{Nb}+\mathrm{V}+\mathrm{Ti}$ & $\mathrm{ACC}$ & Alta & 650 & 710 & 0,92 & 18 \\
\hline 2 & $\mathrm{Nb}+\mathrm{V}+\mathrm{Ti}+\mathrm{Cr}+\mathrm{Mo}$ & $\mathrm{ACC}$ & Baixa & 590 & 690 & 0,86 & 43 \\
\hline 3 & $\mathrm{Nb}+\mathrm{V}+\mathrm{Ti}+\mathrm{Cr}+\mathrm{B}$ & $\mathrm{DQ}$ & Alta & 1180 & 1490 & 0,78 & 14 \\
\hline
\end{tabular}

Tabela 2. Propriedades mecânicas de dureza e energia absorvida obtidas em esboços com diferentes parâmetros de resfriamento no MULPIC e composições químicas.

parâmetros de resfriamento no MULPIC e composições químicas.
\begin{tabular}{|c|c|c|c|c|c|}
\hline $\begin{array}{c}\text { Tipo de } \\
\text { Aço }\end{array}$ & Microligantes & $\begin{array}{c}\text { Modo de } \\
\text { Operação } \\
\text { MULPIC }\end{array}$ & $\begin{array}{c}\text { Taxa } \\
\left({ }^{\circ} \mathrm{C} / \mathrm{s}\right)\end{array}$ & $\begin{array}{c}\text { Dureza } \\
\text { Média* }^{*} \\
(\mathrm{HB})\end{array}$ & $\begin{array}{c}\text { Energia Média } \\
\text { Absorvida a } \\
-60^{\circ} \mathrm{C}(\mathrm{J})\end{array}$ \\
\hline 1 & $\mathrm{Nb}+\mathrm{V}+\mathrm{Ti}$ & ACC & Alta & --- & 360 \\
\hline 2 & $\mathrm{Nb}+\mathrm{V}+\mathrm{Ti}+\mathrm{Cr}+\mathrm{Mo}$ & $\mathrm{ACC}$ & Baixa & --- & 370 \\
\hline 3 & $\mathrm{Nb}+\mathrm{V}+\mathrm{Ti}+\mathrm{Cr}+\mathrm{B}$ & $\mathrm{DQ}$ & Alta & 435 & -- \\
\hline
\end{tabular}

*Dureza média a $2 \mathrm{~mm}$ da superfície.
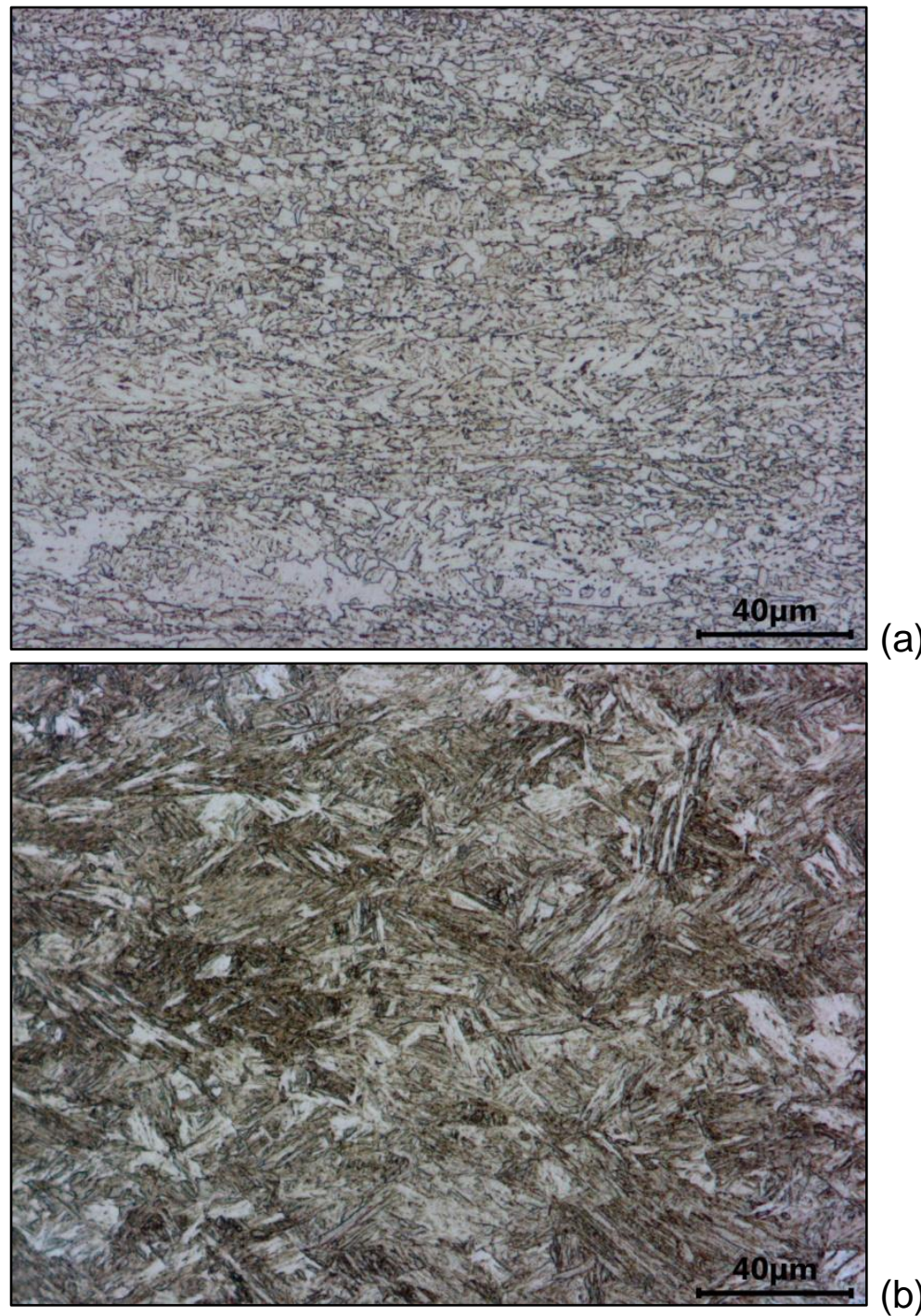

Figura 11: Microestruturas típicas dos aços estudados à $1 / 4$ da espessura com aumento de 500x. Ataque nital a 3\%. (a) Aço processado via ACC, (b) Aço processado via DQ. 
A avançada tecnologia do equipamento MULPIC, conjugado com as técnicas mais modernas de controle de forma (Smart Crown, Bending e Shifting), aliados ao esquema de passes do laminador e da desempenadeira efetivos, conferem ao material excelente planicidade, isento de ondulações, conforme pode ser observado na figura 12.

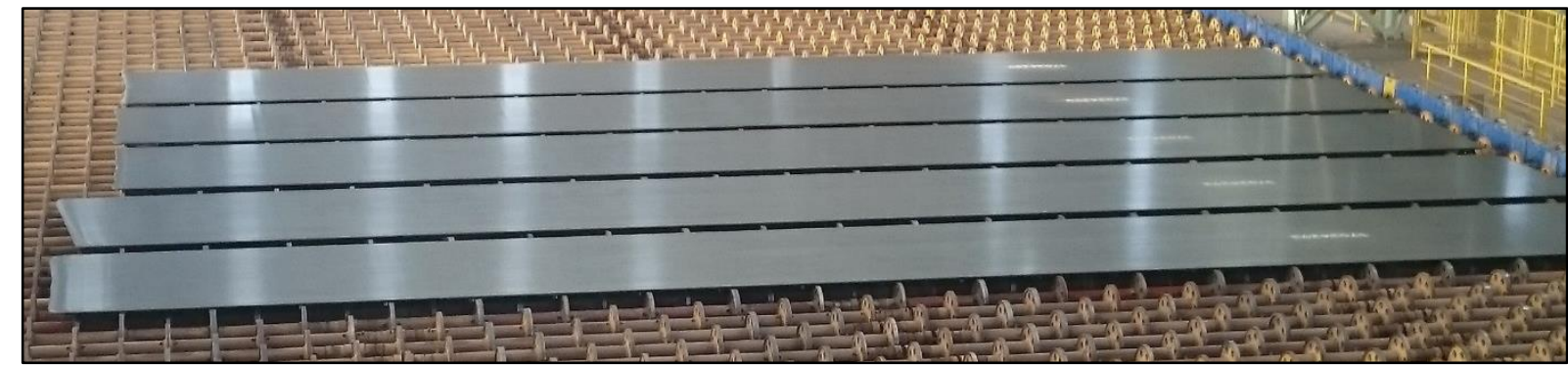

Figura 12: Esboço processado via MULPIC.

\section{CONCLUSÃO}

Em um mercado cada vez mais competitivo, o processo TMCP se destaca pela sua versatilidade na busca de materiais de alta performance e baixo custo, uma vez que permite a obtenção de produtos de alta resistência mecânica com ligas menos carregadas.

O processo TMCP é uma tecnologia que deve ser empregada de forma conjunta, desde o aquecimento da placa até o desempeno do esboço, considerando as particularidades metalúrgicas de cada etapa do processo e os diferentes microligantes utilizados no aço.

\section{REFERÊNCIAS}

1 Rizzo E.M.S. Processos de Laminação a Quente. Associação Brasileira de Metalurgia e Materiais e Mineração - ABM

2 S. Vervynckt, K. Verbeken, B. Lopez and J. J. Jonas, Modern HSLA steels and role of non-recrystallisation temperature, International Materials Reviews 2012, vol. 57, no 4

3 PICHLER, R.; BRAMMER, M.; FARNIK, A. VAI Plate Mill Automation - The Leading Plate Mill Quality Improvement Package. Metal 2003, mai. 2003.

4 SIEMENS VAI. SIROLL Solution for Hot Strip Mills. Metals Technologies, pp. 13-31, 2009.

5 LIN, M., BODNAR, R.L., SHEN, Y. et al., Some Fundamentals for the Accelerated Cooling of Plate Products. In: International Symposium on Steel for Fabricated Structures, 1999, Cincinatti. Materials Park: ASM/AISI, 1999. p. 95-103. 